\title{
Management of failed hypospadias: choosing the right method and achieving optimal results
}

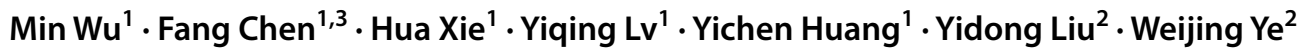

Received: 27 April 2018 / Accepted: 12 August 2018 / Published online: 18 August 2018

(c) The Author(s) 2018

\begin{abstract}
Objective Because of the complexity of the abnormalities and limited options for reconstruction of failed hypospadias, creating a neourethra presents a challenge to surgeons. We reviewed our experiences with staged urethroplasty strategies to repair the penis of failed hypospadias.

Materials and methods We retrospectively reviewed 56 consecutives patients following multiple unsuccessful hypospadias repairs from 2010 to 2016. Patients were divided into the following two groups based on their penile conditions and urethroplasty procedures: staged buccal mucosa graft Bracka urethroplasty (group1) and two-stage urethroplasty with additional buccal mucosa graft augmentation of the dorsal urethral plate (group2).

Result Median follow-ups were 26.5 months (12-59 months) and 28.6 months (14-59 months) in the group 1 and group 2. After the second stage, three patients (11.1\%) in group 1 and two patients $(6.89 \%)$ in group 2 did not have a meatal opening at the top of the glans. Three patients $(11.1 \%)$ in group 1 and 4 patients (13.79\%) in group 2 had urethrocutaneous fistulas. One patient (3.70\%) in group 1 and no patients in group 2 had meatal stenosis. Two patients (6.89\%) in group 2 and no patients in group 1 had urethral strictures; all patients with strictures were cured using dilations, so follow-up surgeries were not required. No patients in either group had signs of diverticulum or residual chordee. Three patients (11.1\%) in group 1 and 4 patients (13.79\%) in group 2 needed reoperations.

Conclusion Failed hypospadias repairs were often due to the underestimation of the penile conditions at the prior surgery. The results indicated that two-staged strategies were preferred for treating complex situations during the intermediate period of our study. Staged buccal mucosa graft Bracka urethroplasty and two-stage urethroplasty with additional buccal mucosa graft augmentation of the dorsal urethral plate severed as reliable approaches in complex hypospadias cases and could improve the overall success rate.
\end{abstract}

Keywords Failed hypospadias · Two-stage urethroplasty · Reoperation

Fang Chen

doctorchenfang@126.com

$\mathrm{Min} \mathrm{Wu}$

wumanrj@sina.com

1 Department of Urology, Children's Hospital of Shanghai, School of Medicine, Shanghai Jiao Tong University, Shanghai, China

2 Department of Urology, Ren Ji Hospital, School of Medicine, Shanghai Jiao Tong University, Shanghai, China

3 Department of Urology, Sixth People's Hospital; Oriental Urethral Reconstructive Center, Jiao Tong University of Shanghai, Shanghai, China

\section{Background}

Hypospadias is a relatively common congenital deformity of the urogenital system affecting approximately $0.3-0.4 \%$ of the population worldwide [1]. The urethral opening is sited anywhere from the glans to the perineum along the underside of the penis. The goal of the initial repair, for which over 300 different techniques are described, is to correct any curvature, ensuring that the penis is straight, allowing for successful intercourse, to create a functional neourethra to direct the urinary stream in a forward direction and to produce a cosmetically normal penile appearance with a slit-like meatus at the tip of the glans [2]. Although surgical techniques have improved dramatically over the past three decades, providing successful function and a good appearance 
using modern techniques, failures and complications do occur, and the pursuit of the ideal repair method still goes on. Failed hypospadias repair is often associated with penile skin loss or deficient local tissue, which leaves the penis short, scarred, and hypovascular. This remains one of the most challenging problems faced by reconstructive surgeons today [3]. When a suitable urethral plate is available, possible strategies for re-operative hypospadias repairs include island onlay flap, as well as tubularized incised plate (TIP) or dorsal inlay graft ("sondgraft") urethroplasty [4]. On the other hand, when significant ventral curvature persists, or the urethral plate is visibly scarred, surgical options for secondary urethroplasty are rather limited. Since the use of buccal mucosa graft was first reported in 1941, it has been widely accepted for patients with multiple prior failed hypospadias procedures and the use of single stage buccal mucosa graft urethroplasty in hypospadias failure has been successful in a few, limited cases [5]. Most studies prefer two-stage urethral reconstruction in complex cases to optimize buccal mucosa graft take and urethral vascularity [6]. Gill suggested that the two-stage Bracka's method might be an alternative technique applicable to various types of hypospadias, including hypospadias cripples [7]. We reviewed our experiences using two stage urethroplasty strategies to repair failed hypospadias.

\section{Materials and methods}

\section{Materials}

We evaluated the records of consecutive patients referred for complex hypospadias from March 2011 to July 2016. The inclusion criteria for complex hypospadias was (1) two or more previous failed hypospadias surgeries, (2) with complications such as dystopic meatus, residual chordee, multiple fistulas, urethral stricture, or diverticulum, and (3) with a short, scarred, or abnormally shaped penis. A total of 56 patients diagnosed with failed hypospadias were included in this study, with ages ranging from 16 to 41 years old, and the number of prior procedures ranging from 3 to 14 (Table 1). Meatal dystopia was present in 53 patients, multiple urethral fistulas (two or more) were present in 49 patients, residual curvature in 51 patients, and strictures in 17 patients. All patients underwent two-stage operations and were classified into the following two groups based on the remaining conditions of the tissue after prior failed reconstructive surgeries: (1) staged buccal mucosa graft Bracka urethroplasty (group 1: patients with too short a praeputium to cover the phallus); (2) two-stage urethroplasty with additional buccal mucosa graft augmentation of the dorsal urethral plate (group 2: patients with adequate prepuce but poor quality due to diverticulum or infection). The outcome was measured in terms of ability to straighten penis, final site of meatal opening, occurrence of complications; such as fistula formation requiring revision surgery and stricture affecting urinary stream. Our institutional ethical review board approved this study.

\section{Staged buccal mucosa graft Bracka urethroplasty}

Complete release of the chordee and excision of scarred skin from the ventral aspect of the penis was performed during the first stage and an artificial erection was achieved to make sure that straightening of the penis had been accomplished. All fibrotic and scarred tissue was removed, and a well vascularized bed was prepared on the tunica albuginea, the urethra was dissected proximally until healthy appearing mucosa was found. Buccal mucosa graft was harvest from the lower lip, and size was to be 15-20\% larger than the area to be covered. Then the graft was stretched and loosely quilted to the previously developed tunica albuginea bed. The second stage was performed 6 months after the initial repair; a U-shaped incision was made along the edges of the graft. The width of the graft was adjusted to the size of the penis and the catheter, which was dissected and raised from the bed enough to allow for tension-free tubularization. A local flap, such as dartos fascia or tunica vaginalis, was separated and used for coverage, which was usually called
Table 1 The pre-operative conditions for patients of the two groups

\begin{tabular}{lll}
\hline Variable & $\begin{array}{l}\text { Staged BMG Bracka urethro- } \\
\text { plasty }(n=27)\end{array}$ & $\begin{array}{l}\text { Two-stage BMG dorsal } \\
\text { UP augmentation } \\
(n=29)\end{array}$ \\
\hline $\begin{array}{l}\text { Age (years) } \\
\text { Median }\end{array}$ & 19 & 22.5 \\
Range & $16-33$ & $16-41$ \\
Previous repairs $(n)$ & & \\
Median & $4.2 \pm 1.1$ & $4.5 \pm 0.8$ \\
Range & $3-14$ & $3-6$ \\
Buccal mucosa graft length $(\mathrm{cm})$ & $7.8 \pm 1.46$ & $6.7 \pm 1.28$ \\
Buccal mucosa graft width $(\mathrm{cm})$ & $1.9 \pm 0.21$ & $1.2 \pm 0.11$ \\
\hline
\end{tabular}


the waterproofing layer (Fig. 1). A 14-16 Fr urethral stent was left in place for 10-14 days.

\section{Two-stage urethroplasty with additional buccal mucosa graft augmentation of the dorsal urethral plate}

One-stage buccal mucosa graft inlay urethroplasty was not appropriate for individuals who lack local heathy tissue or those with a lengthy urethral stricture or giant urethral diverticulum, which might cause chronic infection. The potential disadvantage of this approach was that the graft might not take well to the corporal bodies. If a keloid or contracture was identified after the first stage of staged buccal mucosa graft Brack urethroplasty, an additional revision procedure was needed, which might result in urethral complications and further salvage repairs. For such cases we opted for other two-stage treatment options. In the first stage, a midline incision was made from the meatus of the tip to normal healthy urethral mucosa, the ventral part of stricture or diverticulum was opened and the ventral part of diverticulum was tightly quilted to the corporal bodies with interrupted 6-0 sutures to remold the urethral plate. After 6-12 months, the local skin tissue and urethral plate became healthy and vascularized. A deep midline relaxing incision was made in the urethral plate of the tunica albuginea and the width and length of the
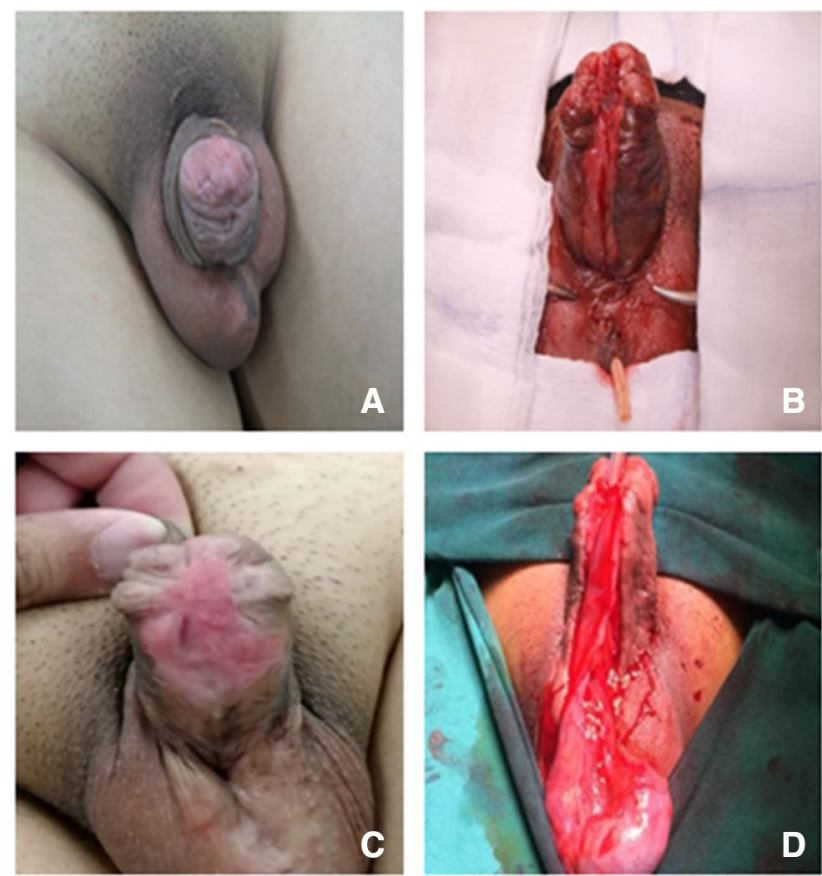

Fig. 1 a Patients labelled "Failed Hypospadias" with severe chordee and scarred surface of penis. b Excision of fibrotic tissue and buccal mucosa graft applied to form the urethral plate. $\mathbf{c}$ Well-healed soft urethral plate after 12 months. d Urethral tube is rolled over catheter and tunica vaginalis flap is separated for coverage of the neourethra urethral defect was measured. The procedure used to harvest the buccal mucosa grafts was mentioned above. Then the urethral plate was tubularized in a continuous fashion over a 14-18 Fr catheter based on urethra size, which was removed on the 21 st postoperative day. The urethra was covered with a subcutaneous dartos patch or other tissues, like the tunica vaginalis, in such a way that the two suture lines are separated (Fig. 2).

\section{Results}

Out of the total of 56 patients, we were able to conduct staged buccal mucosa graft Bracka urethroplasty in 27 patients (group 1) and two-stage urethroplasty with additional buccal mucosa graft augmentation of the dorsal urethral plate procedure in 29 patients (group 2). After the second stage, 3 patients (11.1\%) in group 1 and 2 patients $(6.89 \%)$ in group 2 did not have a meatal opening at top of the glans. Three patients (11.1\%) in group 1 and 4 patients $(13.79 \%)$ in group 2 had urethrocutaneous fistulas. One patient (3.70\%) in group 1 and no patients in group 2 had meatal stenosis. Two patients $(6.89 \%)$ in group 2 and no patients in group1 had urethral strictures. Patients were diagnosed with strictures (one located at the urethral opening and two at the junction of the urethral mucosa grafts) based on voiding symptoms (urination pain or significant dysuria) and urethral dilation. They returned to normal after receiving repeated dilations (once a week, 2-4 weeks), so follow-up surgeries were not required. No patients in either group had signs of diverticulum or residual chordee (Table 2). All complications were discovered within 6 months following the procedure. Three patients (11.1\%) in group 1 and 4 patients $(13.79 \%)$ in group 2 needed reoperations. The five remaining patients with a urethral meatus not at the right part of the glans were satisfied with the final results and declined further surgical intervention. Patients were followed up over a period of 12-59 months; no other complications arose.

\section{Discussion}

Different types of procedures have appeared over the years, and patients that had prior failed surgeries often require multiple revision surgeries throughout their life. Patients with prior multiple failed hypospadias repairs often remain functional or have cosmetic complications which may lead to leaving the penis with little tissue, local skin scarred, and unusable. Despite using a meticulous technique, trying to undergo reconstruction for complex conditions has the potential to fail, even in experienced hands. Complications from this procedure results in discouragement as reported by prior researchers due to the reduced amount of options 
Fig. 2 a Patients labelled "Failed Hypospadias" with small phallus and urethral diverticulum. b Complete midline incision of the urethral diverticulum resulted in urethral defect and scar tissue on the ventral surface. $\mathbf{c}$ Excision of scar tissue, the skin flap is quilted to the ventral surface of the corpus cavernosum. $\mathbf{d}$ In the second stage, urethral tube perimeter is identified and incised. e Midline of the urethral plate and buccal mucosa graft is harvested. $\mathbf{f}$ Urethra is reconstructed and tunica vaginalis flap is separated for coverage of the neourethra
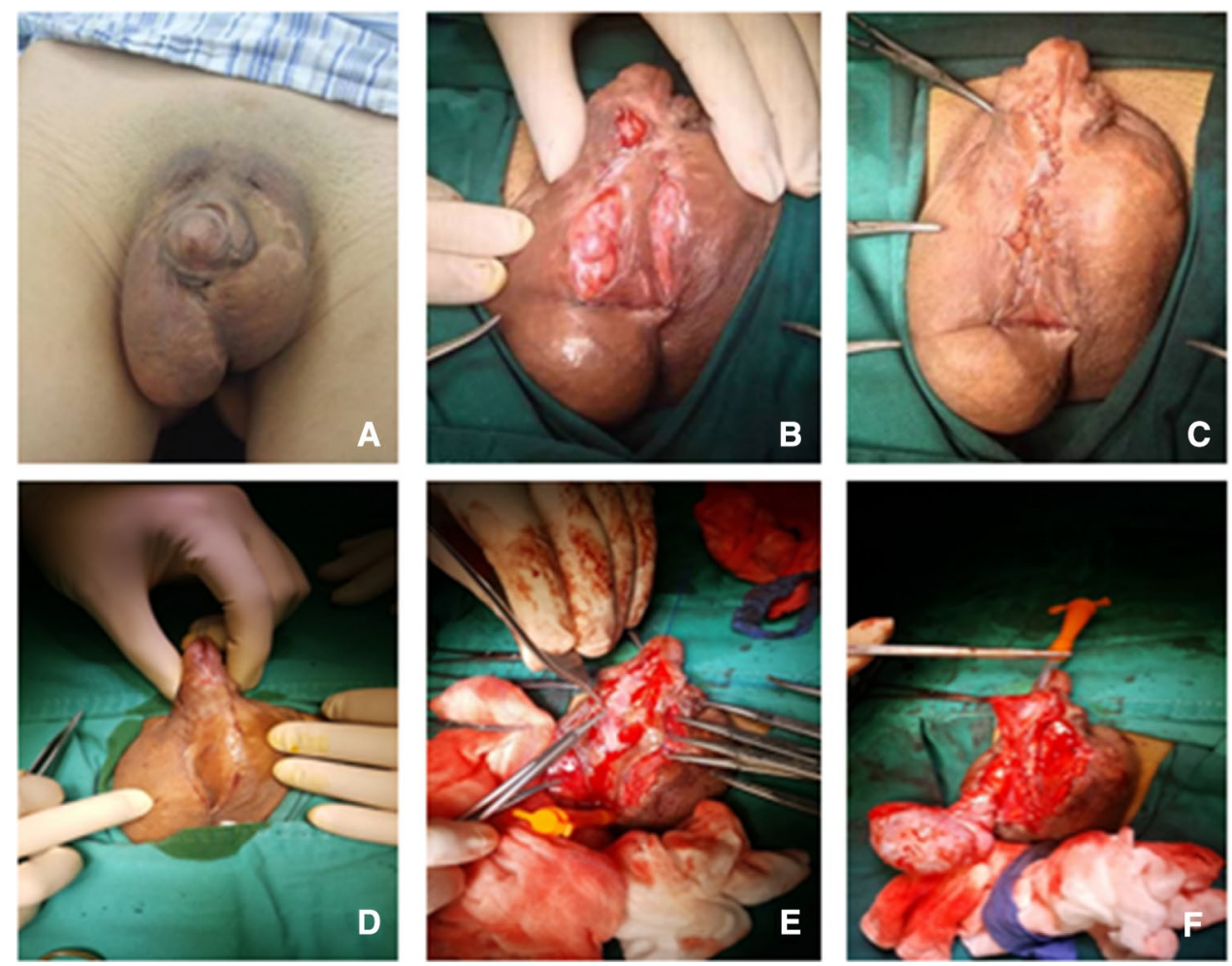

Table 2 Rate of complications following two-stage urethroplasty hypospadias repair

\begin{tabular}{llll}
\hline Complication & $\begin{array}{l}\text { Staged BMG Bracka ure- } \\
\text { throplasty }(n=27)\end{array}$ & $\begin{array}{l}\text { Two-stage BMG dorsal UP } \\
\text { augmentation }(n=29)\end{array}$ & Total $(n=56)$ \\
\hline $\begin{array}{l}\text { Follow-up (months) } \\
\text { Median }\end{array}$ & $26.5 \pm 3.9$ & $28.6 \pm 9.7$ & $27.7 \pm 7.6$ \\
Range & $12-59$ & $14-59$ & $12-59$ \\
$\begin{array}{l}\text { Short/midterm function }(n, \%) \\
\text { Fistula }\end{array}$ & $3(11.1 \%)$ & $4(13.8 \%)$ & $7(12.5 \%)$ \\
$\begin{array}{l}\text { Meatal stenosis } \\
\text { Urethral stricture }\end{array}$ & $1(3.70 \%)$ & - & $1(1.78 \%)$ \\
$\begin{array}{l}\text { Terminal dehiscence } \\
\text { Cosmetic }(n, \%)\end{array}$ & - & $2(6.89 \%)$ & $2(3.57 \%)$ \\
$\begin{array}{l}\text { Meatal opening not at the } \\
\text { top of penis }\end{array}$ & $3(11.1 \%)$ & - & - \\
Success $(n, \%)$ & $20(74.07 \%)$ & $2(6.89 \%)$ & $5(8.93 \%)$ \\
\hline
\end{tabular}

available for reconstruction, such as the presence of fistulae, abnormally shaped penis, paucity of local tissue, and problems with sexual function [8].

Many researchers argued that using a ventral incision in the already ischaemic and scarred urethra will cause the incision site to be susceptible to urethrocutaneous fistulas or complete breakdown of the free graft. The use of a single-stage buccal graft urethroplasty in hypospadias failure was limited to defects $<3 \mathrm{~cm}$, single-stage tubularization of a buccal graft has an unacceptably high stenosis rate [9]. Sondgrass reported a complication rate of approximately
$20 \%$ in redo cases by TIP technique, while Elicevik performed TIP repairs on 100 failed patients and reported a $26 \%$ complication rate [10]. They suggested that it was safe to perform the TIP technique providing the urethral plate was scarless and intact, so redo TIPs should be avoided in complex re-operative patients. It was for these reasons that use of a single-stage urethroplasty for salvage repair, including TIP, buccal onlay graft, and penile skin graft or flap urethroplasty, was available in a few selected redo cases.

Stecker first identified the term "Hypospadias Cripples" to emphasize the difficulty and complexity of the deformities 
faced when trying to revise failed hypospadias cases [11]. Regardless of the physical impact from the complications, labelled individuals "Hypospadias Cripples" may further undermine their feelings and confidence in their sexual selfperception [12]. Bracka [13] modified his two-stage penile skin graft procedure for salvage repair and proposed that this technique was extremely adaptable and capable of producing sophisticated results in any degree of deformity.

If local genital skin is unavailable, buccal mucosa has emerged as the popular tissue of choice. Buccal mucosa gained acceptance due to unique histological features, highly vascularized lamina propria, and thick non-keratinized epithelial layer, which facilitates graft imbibition and angiogenesis. Gill conducted a cohort study of 100 hypospadias cripples cases using a two-staged Bracka's technique (a full-thickness graft of skin or buccal mucosa used for urethral plate reconstruction) showed a fistula rate close to $9 \%$, which could be a greatest achievement given the undesirable patient profile [7]. Another controversy in staged urethroplasty is the treatment of the scarred urethral plate. Some authors argued that the urethral plate should be completely removed since it was usually scarred, unusable, and frequently histologically prone to become lichen sclerosis or balanitis xerotica obliterans. Those that approved preserving the urethral plate stated that in many cases the urethral plate still had sufficient width, which could minimize the amount of buccal mucosa necessary [14].

We knew from the literature that two-stage urethroplasty had been demonstrated to be more reliable than one-stage repairs in failed hypospadias salvage surgery, especially in some cases with scarred skin or chordee [7, 15]. In our study, we performed a retrospective analysis on the two different procedures, combining the buccal mucosa graft and two-stage principle. The success rates for the staged buccal mucosa graft Bracka urethroplasty technique group and the two-stage urethroplasty with additional buccal mucosa graft augmentation of the dorsal urethral plate procedure group were similar, $74.07 \%$ (20/27) versus $74.41 \%$ (21/29). As for outcomes of complications, meatal opening at the tip of the glans was $24 / 27$ versus $27 / 29$, fistulas was $3 / 27$ versus $4 / 29$, and urethral stenosis were $1 / 27$ versus $2 / 29$. Contracture of buccal mucosa graft or partial graft loss during hypospadias salvage surgery was reported by prior studies with a rate range from 3 to $12 \%$ [7, 16, 17]. The finding was dissimilar to our patients in group 1 with previous reports. No revision surgery was required secondary to graft related complication in the repair. The reason for this difference may be because our study excluded the cases with a lengthy urethral stricture or giant urethral diverticulum, which might cause chronic infection and urethral plate with gross scarring. Graft contracture was likely results from inadequate blood supply and scarring along the ventral corporeal bodies following previous failed surgeries, especially associated with urinary extravasation. For these patients, we made a ventral midline incision from the meatus of the tip to the normal healthy urethral mucosa, opened the ventral part of the stricture or existing diverticulum, and quilted the urethral skin to the corporal bodies tightly. After the local skin tissue and urethral plate became healthy and vascularized, without causing chronic inflammation, the two-stage urethroplasty with additional buccal mucosa graft inlay procedure was conducted. Many reports showed that the buccal mucosa graft donor site also had complications, such as persistent perioral numbness, salivary changes, and difficulty in opening the mouth [18]. Preserving the urethral plate could minimize the amount of buccal mucosa graft harvesting and reduced the risk of donor complications. Our study also has the limitation that although only short- and midterm follow-up could be determined, the complication rate seems to be low; however, long-term follow-up is required.

\section{Conclusions}

Management of failed hypospadias repair remains a challenge, and two-stage urethroplasty is generally required when the remaining reconstructed urethra's quality is poor and ischaemic. The staged buccal mucosa graft Bracka urethroplasty technique is a simple and versatile strategy for dealing with the complex conditions encountered during reconstruction, especially when lacking available local skin. The two-stage urethroplasty with additional buccal mucosa graft augmentation of the dorsal urethral plate technique has become a satisfactory method for failed hypospadias patients with unhealthy tissue due to infection of the urethral diverticulum or strictures.

Funding This study was not funded.

\section{Compliance with ethical standards}

Conflict of interest Author Min Wu, Yiqing Lv, Hua Xie, Yidong Liu, Weijing Ye, Yichen Huang, and Fang Chen declare that they have no conflict of interest.

Ethical approval All procedures performed in studies involving human participants were in accordance with the ethical standards of the institutional and/or national research committee and with the 1964 Helsinki declaration and its later amendments or comparable ethical standards.

Informed consent Informed consent was obtained from all individual participants included in the study.

Open Access This article is distributed under the terms of the Creative Commons Attribution 4.0 International License (http://creativeco mmons.org/licenses/by/4.0/), which permits unrestricted use, distribution, and reproduction in any medium, provided you give appropriate credit to the original author(s) and the source, provide a link to the Creative Commons license, and indicate if changes were made. 


\section{References}

1. Kalfa N, Sultan C, Baskin LS (2010) Hypospadias: etiology and current research. Urol Clin North Am 37:159-166

2. Örtqvist L, Fossum M, Andersson M et al (2015) Long-term followup of men born with hypospadias: urological and cosmetic results. J Urol 193(3):975-981

3. Pandey A, Barta-Kelemen AM, Borisenkov M et al (2017) The staged urethroplasty with vascularised scrotal flap and buccal mucosa graft after failed hypospadias surgery: a reliable technique with a Novel Tool. Urol Int 99(1):36-42

4. Borer JG, Bauer SB, Peters CA et al (2001) Tubularized incised plate urethroplasty: expanded use in primary and repeat surgery for hypospadias. J Urol 165(2):581-585

5. Rosenbaum CM, Schmid M, Ludwig TA et al (2016) Redo buccal mucosa graft urethroplasty: success rate, oral morbidity and functional outcomes. BJU Int 118(5):797-803

6. McNamara ER, Schaeffer AJ, Logvinenko T et al (2015) Management of proximal hypospadias with 2-stage repair: 20-year experience. J Urol 194(4):1080-1085

7. Gill NA, Hameed A (2011) Management of hypospadias cripples with two-staged Bracka's technique. J Plast Reconstr Aesthet Surg 64(1):91-96

8. Leslie B, Lorenzo AJ, Figueroa V,et al (2011 Mar) Critical outcome analysis of staged buccal mucosa graft urethroplasty for prior failedhypospadias repair in children. J Urol 185(3):1077-1082

9. Craig JR, Wallis C, Brant WO, Hotaling JM, Myers JB et al (2014) Management of adults with prior failed hypospadias surgery. Transl Androl Urol 3(2):196-204
10. Eliçevik M, Tireli G, Demirali O et al (2007) Tubularized incised plate urethroplasty for hypospadias reoperations in 100 patients. Int Urol Nephrol 39(3):823-827

11. Stecker JF Jr, Horton CE, Devine CJ Jr et al (1981) Hypospadias cripples. Urol Clin North Am 8(3):539-544

12. Kiss A, Sulya B, Szász AM et al (2011) Long-term psychological and sexual outcomes of severe penile hypospadias repair. J Sex Med 8:1529-1539

13. Altarac S, Papeš D, Bracka A (2012) Two-stage hypospadias repair with inner preputial layer Wolfe graft (Aivar Bracka repair). BJU Int 110(3):460-473

14. Nozohoor Ekmark A, Svensson H, Arnbjörnsson E,et al (2015) Failed hypospadias repair: an algorithm for secondary reconstruction using remaining local tissue. J Plast Reconstr Aesthet Surg 68(11):1600-1609

15. van der Werff JFAMD, van der Meulen PhD, Jacques CMD (2000) Treatment modalities for hypospadias cripples. Plast Reconstr Surg 105:600-608

16. Haxhirexha KN, Castagnetti M, Rigamonti W et al (2008) Twostage repair in hypospadias. Indian J Urol 24:226-232

17. Obaidullah AM (2005) Ten year review of hypospadias surgery from a single centre. Br J Plast Surg 58:780-789

18. $\mathrm{Xu} \mathrm{YM}, \mathrm{Xu} \mathrm{QK}, \mathrm{Fu} \mathrm{Q}$ et al (2011) Oral complications after lingual mucosal graft harvesting for urethroplasty in 110 cases. BJU Int 108(1):140-145 